\title{
The evolving role of transarterial chemoembolization in the management of hepatocellular carcinoma
}

\author{
Georgios Tsoulfas \\ Department of Surgery, Aristoteleion University of Thessaloniki, 54622 Thessaloniki, Greece
}

Address for correspondence:

Dr. Georgios Tsoulfas, Department of Surgery, Aristoteleion University of Thessaloniki, 66 Tsimiski Street, 54622 Thessaloniki, Greece. E-mail: tsoulfasg@gmail.com

Received: 26-01-2015, Accepted: 15-02-2015

Globally, hepatocellular carcinoma (HCC) is one of the most frequent causes of cancer-related mortality, being third overall in terms of cancer-related mortality, in addition to being the fifth most common cancer in men and seventh most frequent in women..$^{[1]}$ It represents a complex disease, as it usually develops in a background of cirrhosis, which signifies that in order to properly manage the patient, both issues must be addressed. Based on this, there is a wide range of treatments, depending on the stage and extent of the HCC, as well as on the hepatic function and patient's overall condition. There are curative treatments, including surgical resection and orthotopic liver transplantation for tumors that fall within certain criteria, with liver transplantation having the advantage of addressing both the HCC and the hepatic disease. There are also a variety of locoregional treatments, such as radiofrequency ablation, microwave ablation, irreversible electroporation and transarterial chemoembolization (TACE), which can potentially have a therapeutic role in small lesions (usually $<2 \mathrm{~cm}$ ), or more frequently play a role in the management of more advanced HCC or in patients with poor functional status, either related to their cirrhosis or to overall comorbidities. The first experience with hepatic arterial chemoembolization was in the early $1980 \mathrm{~s}^{[2]}$ Over the years, TACE has managed to gain a lot of attention as it represents a type of treatment

\begin{tabular}{|c|c|}
\hline \multicolumn{2}{|c|}{ Access this article online } \\
\hline \multirow[b]{2}{*}{$\begin{array}{l}\text { Website: } \\
\text { http://www.hrjournal.net/ }\end{array}$} & Quick Response Code \\
\hline & \\
\hline DOI: & \\
\hline $10.4103 / 2394-5079.153287$ & لנ \\
\hline
\end{tabular}

with limited stress for the patient, which has been shown to offer significant advantages. That is not to say that there are no side effects, as the patients after a treatment can experience abdominal pain, fever, nausea, emesis, hepatic and gallbladder inflammation and possible infection. However, given its efficacy in different stages of the disease, the challenge remains identifying its proper role and place in the continuum of care for these patients.

Transarterial embolization involves the transcatheter delivery of either solid particles or coils (transarterial embolization) or chemoembolization (TACE) or chemoembolization using drug-eluting beads (DEB-TACE) or radioembolization (for example with Yttrium-90 microspheres). A more recent endeavor is the use of targeted radionuclide therapy, which is an elegant step towards increased targeted therapy. ${ }^{[3]}$ Overall, it is considered that transarterial embolization by itself is not enough, as with minimal extra effort we could offer these patients much more if the chemotherapy is included. In a review of available literature up to October 2013 by a Canadian group, it was concluded that TACE does offer a survival benefit to these patients, and that DEB-TACE (although it may have a slightly better safety profile compared to TACE) is equivalent to standard TACE regarding increased overall survival. ${ }^{[4]}$

Despite these encouraging results, there are several questions that need to be taken into consideration, regarding both the validity of our data, as well as the evolution of our practices. Although TACE can be used in other diseases and organs as well, this editorial will mainly comment on its application in the liver. Specifically, we have to understand that the success of the method depends significantly on the technical characteristics, that is whether we are using chemotherapy or DEB or radiation microspheres, ultimately this may affect the end-result. In 
addition, apart from what is being delivered, it is essential that it is delivered correctly, which means that the interventional radiologist has to aim for lobar or sublobar branches of the hepatic artery and not simply deliver the therapeutic regimen to the main hepatic artery, as this will include the liver as a whole and create more side-effects by affecting an alreadyfragile remaining healthy liver. Significant progress and improvement in the results have been seen in the last decade or so when microcatheters have been increasingly used, thus providing more accuracy in the delivery. Furthermore, although the preferred treatment in patients with cirrhosis and tumors within the Milan criteria is liver transplantation, TACE has been shown to have either a neoadjuvant role of sorts by providing a downstaging or bridging therapy or an adjuvant treatment role (alone or with sorafenib) in the case of HCC recurrence, which is the main problem after liver transplantation. ${ }^{[5]}$ There is also a significant ongoing discussion regarding the contraindications in the use of TACE, as these are also evolving with the once absolute contraindication of portal vein thrombosis, now being a relative one with proper patient selection. ${ }^{[6]}$ Finally, when discussing a treatment, it is important to have ways of assessing its efficacy, other than patient overall survival. In the case of TACE, this has led to the use of the assessment of re-treatment with TACE prognostic system in the case of multiple treatments and to the modified Response Evaluation Criteria in Solid Tumors criteria..$^{[7]}$

Although the above may mean that there still several unresolved issues regarding the use of TACE in the treatment of HCC, the key fact remains that the technique continues to evolve and as we understand more about tumor biology, it will be easier to identify those patients that will benefit the most from this treatment.

\section{REFERENCES}

1. Bosetti C, Turati F, La Vecchia C. Hepatocellular carcinoma epidemiology. Best Pract Res Clin Gastroenterol 2014;28:753-70.

2. Yamada R, Sato M, Kawabata M, Nakatsuka H, Nakamura K, Takashima S. Hepatic artery embolization in 120 patients with unresectable hepatoma. Radiology 1983;148:397-401.

3. Dash A, Knapp FF, Pillai MR. Targeted radionuclide therapy - an overview. Curr Radiopharm 2013;6:152-80.

4. Boily G, Villeneuve JP, Lacoursière L, Chaudhury P, Couture F, Ouellet JF, Lapointe R, Goulet S, Gervais N; Comité de L'évolution des Pratiques en Oncologie. Transarterial embolization therapies for the treatment of hepatocellular carcinoma: CEPO review and clinical recommendations. HPB (Oxford) 2015; 17:52-65.

5. Gamblin TC, Geller DA. Downstaging hepatocellular carcinoma prior to liver transplantation. Liver Transpl 2005;11:1466-8.

6. Xue TC, Xie XY, Zhang L, Yin X, Zhang BH, Ren ZG. Transarterial chemoembolization for hepatocellular carcinoma with portal vein tumor thrombus: a meta-analysis. BMC Gastroenterol 2013;13:60.

7. Sato Y, Watanabe H, Sone M, Onaya H, Sakamoto N, Osuga K, Takahashi M, Arai Y; Japan Interventional Radiology in Oncology Study Group-JIVROSG. Tumor response evaluation criteria for HCC (hepatocellular carcinoma) treated using TACE (transcatheter arterial chemoembolization): RECIST (response evaluation criteria in solid tumors) version 1.1 and mRECIST (modified RECIST): JIVROSG-0602. Ups J Med Sci 2013;118:16-22.

How to cite this article: Tsoulfas G. The evolving role of transarterial chemoembolization in the management of hepatocellular carcinoma. Hepatoma Res 2015;1:9-10.

Source of Support: Nil. Conflict of Interest: None declared. 